\title{
Nuestras luchas de ayer: voces militantes y narrativas generacionales sobre la derrota y los desafíos actuales de la izquierda chilena (1990-2018) ${ }^{1}$
}

\section{Carmen Gemita Oyarzo Vidal ${ }^{2}$}

Fecha de recepción: 16 de marzo de 2019

Fecha de aceptación: 6 de mayo de 2019

Fecha de publicación: 30 de julio de 2019

\begin{abstract}
Resumen
Este artículo presenta parte de los resultados de una investigación en curso que indaga las transformaciones identitarias de los militantes de izquierda en la postdictadura chilena (1990-2019). Mediante el análisis de entrevistas biográficas (26 casos), el trabajo explora una interpretación generacional de la experiencia militante. A partir de una revisión crítica de su participación en la lucha antidictadura, los entrevistados abordan las razones de la desmovilización de la década de los 90, los temas pendientes de la democracia y los desafíos actuales de la izquierda chilena. La discusión de resultados afirma que los militantes y exmilitantes se definen como actores secundarios de la transición y de los debates actuales de la nueva izquierda chilena. Esta narrativa generacional es explicada por la falta de reconocimiento social y político de las experiencias colectivas de lucha.
\end{abstract}

Palabras clave: democracia chilena, identidades generacionales, militantes de izquierda, lucha antidictatorial, postdictadura

Los datos presentados en este artículo son parte de una investigación financiada por CONICYT-Fondecyt, proyecto $\mathrm{N}^{\circ}$ 3170298. Investigadora responsable: Carmen Gemita Oyarzo Vidal.

2 Socióloga, Universidad de Concepción. Dra. en Estudios Americanos, Universidad de Santiago. Investigadora asociada del Instituto de Investigación en Ciencias Sociales de la Universidad Diego Portales (ICSO-UDP), Escuela de Ciencia Política. Contacto: carmen.oyarzo.fcsh@mail.udp.cl 


\title{
Our struggles of yesterday: militant voices and generational narratives about defeat and current challenges of the Chilean left (1990-2018)
}

\begin{abstract}
This paper presents some results collected in an ongoing research study on left-wing militancy transformation in post-dictatorship in Chile. Through qualitative research based on biographical interviews (26 cases), the article explores a generational interpretation of militant experiences. From a critical review of their political participation in the anti- dictatorship struggle, the interviewees address: 1) the reasons for demobilization during the 90s; 2) the pending issues of democracy and; 3 ) the current challenges of the Chilean left. The discussion of results asserts that the militants and former militants see themselves as a generation of supporting actors for the political transition and further discussion of the new Chilean left. This generational narrative is explained by the absence of social and political recognition of the collective experiences of struggle.
\end{abstract}

Keywords: Chilean democracy, generational identities, left-wing militants, anti-dictatorship struggle, post-dictatorship

\section{Nossas lutas de ontem: vozes militantes e narrativas geracionais sobre a derrota e os desafios atuais da esquerda chilena (1990-2018)}

\section{Resumo}

Este artigo apresenta parte dos resultados de uma pesquisa em andamento que indaga nas transformações identitárias dos militantes de esquerda na pós-ditadura chilena (1990-2019). Através da análise de entrevistas biográficas (26 casos), o trabalho explora uma interpretação geracional da experiência militante. A partir de uma revisão crítica de sua participação na luta contra a ditadura, os entrevistados abordam as razões da desmobilização da década dos anos 90, os temas pendentes da democracia e os desafios atuais da esquerda chilena. A discussão de resultados afirma que os militantes e ex-militantes se definem como atores secundários da transição e dos debates atuais da nova esquerda chilena. Esta narrativa geracional é explicada pela falta de reconhecimento social e político das experiências coletivas de luta.

Palavras-chave: democracia chilena, identidades geracionais, militantes de esquerda, luta antiditatorial, pós-ditadura

\section{Introducción}

El presente artículo es parte de un proyecto de investigación mayor que indaga las transformaciones de la militancia política en el Chile de la postdictadura (1990-2016). Debido a su exten- 
sión, este escrito aborda dos dimensiones específicas de la transformación identitaria de los militantes y exmilitantes de izquierda: mediante una problematización generacional de la identidad política, el trabajo revisa la evaluación que los militantes hacen de su participación en la lucha antidictadura y el modo en que piensan los desafíos actuales de la izquierda chilena.

Así, el artículo se divide en cuatro apartados generales. El primer apartado, titulado "Transformaciones de la izquierda chilena (1973-1990): antecedentes y perspectivas de análisis", discute los principales enfoques del estudio del militantismo y justifica la necesidad de construir un concepto empírico de identidad generacional. El segundo apartado, presenta las consideraciones metodológicas de nuestro uso de la perspectiva biográfica, los criterios de selección de casos y la construcción de categorías de análisis. El tercer apartado de análisis está subdividido en cuatro secciones que organizan la discusión de resultados: 1) luchas y derrotas; 2) razones de la desmovilización; 3) temas pendientes de la democracia; 3) miradas de Chile actual y desafíos de la nueva izquierda chilena. En el cuarto y último apartado, comentamos la validez del concepto de "identidad generacional", del cual surgen las principales hipótesis interpretativas sobre las narrativas generacionales de los militantes, quienes construyen una definición de sí mismos como actores secundarios de la política.

\section{Transformaciónes de la izquierda chilena (1973- 1990): antecedentes y perspectivas de análisis}

La revisión del derrotero de los partidos de izquierda en el periodo 1973-1990 permite reconocer con claridad tres periodos de crisis y profunda transformación identitaria de sus militantes: en primer lugar, el quiebre democrático de 1973 deja en evidencia la importancia de las alianzas políticas para impulsar procesos de transformación social. Luego, el impacto de la represión política impulsa relaciones de solidaridad y el desarrollo de una cultura de derechos humanos que, hasta entonces, no había existido en 
la izquierda. En segundo término, la movilización antidictatorial alimenta las esperanzas en una salida insurreccional a la dictadura que devolviera a los sectores populares el lugar que habían perdido en la contienda política chilena. Por último, la transición a la democracia, bajo el marco legal de la dictadura, marca una segunda derrota del proyecto popular de las izquierdas; en su proceso de institucionalización (1987-1990), los partidos pierden sus vínculos con la movilización social. Finalmente, la profesionalización de la participación política en los gobiernos democráticos genera dinámicas excluyentes tanto al interior de los partidos como en la administración del Estado.

Respecto de las causas de la crisis institucional de la Unidad Popular, la difundida tesis politológica de Arturo Valenzuela (1989) centra su explicación en el problema del presidente minoritario y en la inestabilidad del centro político representado por el Partido Demócrata Cristino (PDC). Con un 36\% de los votos obtenidos por Salvador Allende en la elección presidencial, era técnicamente imposible impulsar reformas tan profundas y que requerían de amplias mayorías sociales y políticas (p. 117). En esta misma línea de argumentación, otros autores (Corvalán, 2000; Moulian, 2006, 2008; Winn, 2013) defienden también la tesis del empate de fuerzas políticas. Desde un punto de vista macro político, estos trabajos explican la polarización por el desborde de expectativas que generaron los procesos de reformas de los gobiernos de Eduardo Frei Montalva (1964-1970) y Salvador Allende (1970-1973): la división de la izquierda entre gradualistas y revolucionarios, junto con la extrema ideologización de la Democracia Cristiana, que terminó aliándose con la derecha unificada en el Partido Nacional (PN), hicieron imposible, en la práctica, la construcción de una mayoría política que le diera soporte al plan de reformas.

Brutalmente reprimidos y diezmados por los servicios de seguridad de la dictadura, los partidos de izquierda sobreviven en la clandestinidad y en el exilio. Abatidos y perplejos, discuten las razones del fracaso de la Unidad Popular y sus concepciones 
del socialismo. Sin embargo, en los primeros años, están lejos de elaborar una explicación coherente sobre la crisis política. Entre 1973 y 1978 el problema más urgente que deben resolver es la sobrevivencia ante el asedio de la represión. En este contexto de persecución política, la importancia de la unión de todas las fuerzas progresistas para recuperar la democracia vuelve a reflotar, convirtiéndose en una preocupación importante para los partidos Comunista y Socialista. Sin embargo, los intentos por articular un solo frente antifascista respaldado por de la Democracia Cristiana no prosperaron. Con el referéndum del régimen autoritario (1978) y la promulgación de la Constitución de 1980, la discusión más importante de la izquierda fue cómo terminar con una dictadura que había llegado para perpetuarse en el poder (Álvarez, 2011; Muñoz, 2017).

Así, el rol que jugó la represión política es fundamental para comprender cómo las izquierdas redefinieron sus estrategias de lucha. Entre 1977 y 1980 y luego de diversas discusiones internas, los partidos Socialista (PS Almeyda ${ }^{3}$ y Comunista (PC), y el Movimiento de Izquierda Revolucionaria (MIR) definen diversas estrategias de lucha insurreccional contra la dictadura, las cuales adquirirán su sentido práctico en la Jornadas de Protesta Nacional (1983-1986). Más que una confrontación abierta contra las fuerzas armadas regulares, todos los modelos insurreccionales suponían que su éxito dependía de la combinación de diversas formas de lucha y de un fuerte respaldo popular. Las formas que adquirió la protesta callejera en un clima de creciente violencia contra la movilización popular, hicieron pensar a los partidos de

En el caso del PS, el liderazgo de Clodomiro Almeyda se consolida luego de la expulsión de su secretario general, Carlos Altamirano, en 1979. Después de su expulsión, Altamirano forma el Partido Socialista renovado. En el contexto de la movilización nacional, los socialistas renovados se articulan en el Bloque Socialista, junto a la Izquierda Cristiana y al Movimiento de Acción Popular Unitaria (MAPU). Sin embargo, en ese momento no tienen la fuerza para formar una tercera alternativa política a la dictadura. Para más detalles sobre la división del Partido Socialista en dictadura y sobre los contenidos principales del proceso de renovación socialista, ver los trabajos historiográficos de Cristina Moyano (2011) y Víctor Muñoz (2017). 
izquierda que la alternativa insurreccional no solo era una forma de lucha legítima contra la opresión de una cruenta dictadura, sino también un diseño políticamente viable para salir de ella. Sin embargo, todavía debían enfrentar los dilemas políticos que definió el proceso de recomposición de partidos en los momentos más álgidos de la movilización antidictatorial ${ }^{4}$.

Si los años 1983 y 1984 mostraron la fase ascendente de la estrategia de la movilización nacional contra la dictadura, 1985 y 1986 marcaron el momento en que los partidos de la oposición discutieron la viabilidad de las estrategias de salida. En este contexto, el Partido Comunista se juega la última carta de su Política de Rebelión Popular de Masas, a través de la Operación Siglo XX. Además de un acto de ajusticiamiento, la muerte de Pinochet buscó generar una crisis interna al interior de la Junta Militar que favoreciera la sublevación nacional. Sin embargo, en lugar de un alzamiento popular, el fracaso de la operación dividió irremediablemente a la oposición. La izquierda, además, debió enfrentar las fuertes represalias del régimen a manos de la Central Nacional de Informaciones (CNI entre 1977 y 1989)(Oyarzo, 2018, p. 244).

Es así como, en los últimos años de la dictadura (1987-1990) y en plena preparación del plebiscito de 1988, los partidos de la oposición comienzan su proceso de institucionalización y cambian la relación con sus militantes y la evaluación de las formas de lucha: el Movimiento Democrático Popular (MDP) se disuelve en 1987 y sus partidos enfrentan la disyuntiva de incorporarse al proceso electoral ${ }^{5}$. La Concertación por el NO (1988) y, más

\footnotetext{
4 El Partido Socialista de Almeyda se inclina por la tesis de la lucha de masas, rupturista con perspectiva insurreccional. El Partido Comunista define la Política de Rebelión Popular de Masas (PRPM) y el MIR, que había nacido como una organización político militar, se inclina por la versión vietnamita de la tesis maoísta de la guerra popular prolongada.

5 En paralelo, el éxito de la movilización social de 1983 impulsa el proceso de recomposición y legalización de los partidos políticos proscritos en dos grandes fuerzas: 1) Alianza democrática (AD), compuesta por la Democracia Cristiana, Partido Radical y una parte de la llamada derecha republicana y; 2) el Movimiento
} 
tarde, la Concertación de Partidos por la Democracia (1989-2012) surgen de la alianza entre la Democracia Cristiana, los socialistas renovados (que antes estaban en el Bloque Socialista), el Partido Radical y el Partido por la Democracia (PPD), partido instrumental creado por Ricardo Lagos para enfrentar el plebiscito y las elecciones presidenciales de 1989. El itinerario de la transición a la democracia había sido trazado.

Con el triunfo de Aylwin comienza el desafío de la administración del Estado y se materializa la unificación del Partido Socialista de Chile (1990). Atrás quedan los días de un proyecto político de izquierda alternativo al orden dictatorial que representó el MDP: después de la crisis, algunos militantes del PC y del MIR pasarán al Partido Socialista unificado y al PPD. Otros, sencillamente se desvincularán. El PC quedará excluido del parlamento por 19 años, hasta las elecciones presidenciales y parlamentarias de $2009^{6}$.

Sobre el proceso de institucionalización de los partidos de la Concertación, existen varios e importantes estudios basados en la reconstrucción de trayectorias políticas (Hite, 2000; Moyano, 2009, 2011; Espinoza, 2010; Álvarez, 2011; Cuevas, Morales et al., 2015; Cuevas, 2015; Muñoz, 2017). Sin embargo, la mayoría de los trabajos referidos han definido como unidad de análisis principal a los miembros de las elites políticas que hicieron carreras exitosas en los gobiernos de la Concertación de Partidos por la Democracia (1990-2012). Sin duda alguna, la reconstrucción de las trayectorias de las elites son insumos muy importantes para problematizar las complejidades de los procesos de institucionalización partidaria y de la administración del Estado. Así también, son de un valor extraordinario para identificar las redes y

Democrático Popular (MDP), conformado por el Partido Socialista de Almeyda, el Partido Comunista y el Movimiento de Izquierda Revolucionaria (MIR).

$6 \quad$ Luego del acuerdo electoral por omisión entre la Concertación y el PC para derrocar a la derecha, las elecciones parlamentarias de 2009 terminan con la exclusión del PC, que logra elegir 3 diputados: Guillermo Tellier gana las comunas de Pedro Aguirre Cerda y San Miguel (33.49\%); Lautaro Carmona, Copiapó y Tierra Amarilla (28,42\%); y Hugo Gutiérrez, Iquique y Alto Hospicio (30, 53\%). 
las influencias culturales que definen a la elite dirigente. No obstante, el seguimiento de estas trayectorias no muestra las lógicas de exclusión que supone la conformación de estas mismas elites políticas ni, mucho menos, cómo se transformaron los vínculos entre los partidos chilenos y sus bases sociales en un periodo crucial de nuestra historia política.

Es por eso que, siguiendo la tendencia de los estudios de Pirker (2007), Ollier (2009) y Bosi (2016) sobre los procesos de reconversión de militantes en El Salvador, Argentina e Irlanda del Norte respectivamente, nuestro trabajo rescata el valor metodológico de la perspectiva biográfica, poniendo especial atención a las trayectorias de los militantes de base o que ocuparon posiciones intermedias en sus organizaciones, por ser quienes construyen las redes con la movilización social. Los estudios de Pirker y Bosi muestran de manera consistente que la continuidad o discontinuidad del trabajo comunitario y de los vínculos sociales forjados en fases ascendentes de una movilización social, constituyen un hallazgo empírico muy importante para estudiar los procesos de reconversión política, especialmente en el caso de los militantes que pertenecieron a organizaciones político militares. Por su parte, Ollier muestra el contraste entre los cambios públicos y privados de la izquierda argentina, y el impacto de la valoración de la democracia entre los militantes revolucionarios que se convirtieron en sujetos de las nacientes políticas de derechos humanos durante la transición argentina ${ }^{7}$.

Así, en trabajos anteriores (Oyarzo, 2017, 2018), hemos defendido la importancia de estudiar el fenómeno del militantismo desde una perspectiva que profundice las dimensiones subjetivas

\footnotetext{
7 Pirker estudia el cambio de las relaciones entre militantes sindicales y campesinos con el Frente Farabundo Martí, mientras que Bosi explica el proceso de reconversión al trabajo comunitario de los soldados rasos del Ejército Republicano Irlandés (IRA) por su vínculo previo con distintas comunidades cristianas. Ollier (2009), estudia los procesos de reconversión de los militantes revolucionarios de los años 70 en Argentina.
} 
del compromiso político, rescatando las voces de los militantes de base y de aquellos que ocuparon cargos de coordinación territorial y regional durante la dictadura. Estas voces constituyen una pieza clave para comprender cómo se transformaron los vínculos entre los partidos chilenos y la movilización social: la desvinculación y/o la cooptación de una generación completa de militantes que habían mediado y dinamizado la relación entre los partidos y diversas bases sociales que conformaron la oposición a la dictadura, es una evidencia empírica relevante para problematizar los cambios en las lógicas de participación política. Por otro lado, nuestras experiencias de investigación muestran que cuando los entrevistados reconstruyen los pasajes más importantes de su compromiso militante y las dinámicas de inclusión y exclusión política de principios de los noventa, tienden a elaborar narrativas y explicaciones generacionales de su participación política.

Por esta razón, este artículo explora una interpretación generacional de las experiencias militantes. No obstante, nuestra aproximación a la sociología de las generaciones no busca la construcción de un concepto abstracto de generación (Manheim, 1993; Lecardi y Feixa, 2011). Tampoco es un estudio centrado en el modo en que los miembros de distintas cohortes etarias reconstruyen las vivencias de un pasado traumático, como lo muestran varias y destacables investigaciones de caso en el campo de la postmemoria (Cornejo et al., 2013; Aguilar y Ramírez, 2017; Cornejo y Rocha, 2018). En base a los trabajos de Muñoz (2011), González (2012, 2015, 2016) y Longa (2017) sobre juventudes y generaciones, este artículo propone la construcción de un concepto empírico de "identidad generacional", que ayude a identificar los contenidos que articulan la narrativa de los militantes.

\subsection{Hacia un concepto empírico de "identidad generacional"}

La revisión de los enfoques generacionales muestra que no es posible dar cuenta empíricamente de las generaciones en sí 
mismas, sino de tipos específicos de identidades generacionales. En su trabajo sobre La construcción histórica de la de la juventud en América Latina, González y Feixa (2012) hablan de "metáforas generacionales" para explicar que las generaciones son referentes simbólicos que hacen posible la identificación de los agentes socializados en las mismas coordenadas temporales (p. 75). En sus investigaciones posteriores, González $(2015,2016)$ persevera en su intento por construir un concepto amplio y flexible de "identidad" que aborde la vasta gama de cambios culturales que definen a juventudes diversas y que le permita revisar procesos contrapuestos de politización y despolitización juvenil. Muñoz (2011) y Longa (2017), por su parte, acuñan el concepto de "generación política" como una propuesta para analizar a grupos de militantes que participan de ciclos específicos de movilización social.

A partir de una revisión crítica de la obra de Mannheim (1923), Muñoz (2011) y González et al. (2012) señalan que lo más rescatable de su legado teórico es la problematización del tiempo y el carácter relacional de las identidades. Así, la construcción de una identidad generacional surgirá siempre de la referencia mutua entre actores. Por eso, en el proceso de reconocimiento de su lugar en la historia, los miembros de una cohorte están obligados a construir un lazo particular con otros actores del pasado y/o a imaginar una relación con sus contemporáneos y con las nuevas generaciones. Esta aproximación de los lazos intergeneracionales muestra la dificultad para encontrar los límites de una generación y también para reconocer las fronteras que distinguen a una generación de otra.

Haciéndose cargo del carácter controversial del concepto y sin transar con la importancia teórica de la acción política de los miembros de una generación, Longa (2017) encuentra en el concepto de "identidad colectiva" de Alberto Melucci (2002) una aproximación más adecuada para pensar la experiencia social de las generaciones. Al adoptar este enfoque, la identidad generacional es un tipo específico de identidad colectiva que le permite 
vincular el concepto de "generación" con el de "movimiento social". Esta asociación teórica es útil para encontrar las continuidades y rupturas entre las formas organizativas y las subjetividades políticas a través del tiempo (p. 219).

Por tanto, el concepto de "generación política" es heurístico allí donde da cuenta de las orientaciones de la acción (colectiva) de determinados grupos que participan en los movimientos sociales. En términos más sencillos, las generaciones políticas son grupos de militantes que, además de coexistir en un mismo periodo de tiempo, comparten también esa existencia como un colectivo de identidad. Bajo este prisma, el trabajo empírico con las generaciones consiste, precisamente, en rescatar los sentidos de las experiencias que crean lazos (a la manera de Mannheim). En nuestros casos, la lucha ética contra la dictadura, así como sus diversas prácticas colectivas, serían la instancia que crea el vínculo entre los distintos participantes de la movilización social.

A partir de esta discusión, no parece productivo interrogarnos, en términos esencialistas, si existe en la realidad un fenómeno empírico llamado "generación". En un primer nivel de análisis es posible definir las "identidades generacionales" como: los diversos procesos de reconocimiento e identificación mediante los cuales, los miembros de una misma cohorte etaria se piensan a sí mismos como pertenecientes a un mismo tiempo social e histórico. De este modo, la transformación identitaria de los militantes de izquierda no puede considerarse sencillamente un correlato de la historia de los partidos políticos inmersos en determinados ciclos históricos de movilización social. Una definición generacional de la identidad política exige mostrar visiones contrapuestas sobre la historia y, especialmente, una problematización del rol que les correspondió desempeñar a grupos sociales específicos de actores en aquellas luchas políticas que los definieron.

En un segundo nivel de análisis, la configuración de las identidades generacionales surge de las formas particulares de otorgar sentido a la experiencia social, histórica y política compartida 
por los miembros de un mismo grupo de edad. Dicha experiencia compartida se forjará siempre en referencia a la experiencia generacional de otros miembros del mismo grupo de edad y de otras generaciones. Esta definición permite identificar otros componentes que ayudan a reconocer empíricamente la presencia de una narrativa generacional de la experiencia política. Entonces, hablaremos operacionalmente de identidades generacionales cuando un grupo presenta:

a) Una definición de sí mismos como miembros de una comunidad que comparte vivencias similares de ciertos eventos históricos, políticos y culturales.

b) Una problematización similar de los vínculos con las generaciones anteriores. Dichos vínculos pueden definirse por medio de mecanismos de evocación nostálgica, solidaria, conflictiva o de negación del papel de otras generaciones.

c) Una definición del rol político, social o cultural que les corresponde desempeñar, el cual dependerá de sus vínculos con las generaciones anteriores y también con las futuras.

d) Una definición particular de sus prácticas sociales y estéticas.

Con base en esta conceptualización, la discusión de resultados de investigación propone dos hipótesis interpretativas centrales:

a) Los militantes y exmilitantes se definen a sí mismos como participantes de una misma experiencia colectiva. El impacto ético y político de la participación en la lucha más dura contra la dictadura es el hito que forja su identidad generacional, de manera transversal e independiente de su filiación político partidaria.

b) La falta de reconocimiento social y político de sus experiencias de lucha, los lleva a construir una evocación nostálgica de los lazos comunitarios forjados en dictadura y una definición de sí mismos como actores secundarios de la transición. La sensación de haber quedado 
relegados de la historia se repite tanto en su referencia a las viejas generaciones como a las nuevas.

El análisis de casos nos mostrará la validez de nuestra primera conceptualización y la utilidad de las perspectivas generacionales para el estudio de las transformaciones identitarias de los militantes y sus procesos de reconversión política.

\section{Metodología}

Por tratarse de un estudio centrado en la reconstrucción de las experiencias militantes, optamos por un diseño cualitativo de investigación amparado en entrevistas biográficas. La comparación de casos está basada en los aportes de Olivier Fillieule (2015), para quien el seguimiento de las trayectorias biográficas permite reconocer las interacciones significativas que explican el compromiso político: el rol del grupo de pares y de la vinculación con distintas organizaciones constituyen una clave para comprender los cambios de la carrera militante. Luego, el análisis de aspectos comparables de las trayectorias biográficas permite reconocer las continuidades y discontinuidades de la participación política, de la inserción laboral y económica, entre otras fases del ciclo vital de los militantes.

\subsection{Criterios de selección de casos}

Esta investigación consideró tres criterios básicos de selección de informantes: 1) año de reclutamiento (décadas 1970-1980); 2) género; y 3) tipo de militancia: a) base; b) cargos de coordinación territorial en distintas regiones; c) miembros de grupos armados.

Los entrevistados fueron contactados a través de la articulación de redes informales con miembros de los partidos Socialista (Almeyda y Coordinadora Nacional de Regionales); Comunista y el Movimiento de Izquierda Revolucionaria. La activación de redes de conocidos fue muy importante para encontrar los casos y gene- 
rar confianza con los entrevistados que cumplieran con los criterios señalados. De junio de 2017 a enero de 2019 han sido entrevistados 26 casos (16 varones y 10 mujeres) de militantes y exmilitantes, de un total de 30 considerados en esta investigación (cuadro 1).

Cuadro 1

Sintesis de casos

\begin{tabular}{|l|c|}
\hline Organización política & Casos \\
\hline Partido Socialista de Almeyda (PS Almeyda) & 7 \\
\hline Partido Socialista Coordinadora Nacional de Regionales (CNR) & 1 \\
\hline Juventudes Comunistas & 3 \\
\hline $\begin{array}{l}\text { Partido Comunista (PC)- Frente Patriótico Manuel Rodríguez } \\
\text { (FPMR) }\end{array}$ & 6 \\
\hline Movimiento de Izquierda Revolucionaria (MIR) & 9 \\
\hline Entrevistas realizadas & $\mathbf{2 6}$ \\
\hline
\end{tabular}

\subsection{Aplicación de entrevista biográfica}

La pauta de conversación fue aplicada en dos sesiones de entrevista de una hora de duración cada una. Sesión 1: a) síntesis de la militancia en dictadura; b) aprendizajes y evaluaciones de la militancia; c) desvinculación o pasaje a otros partidos. Sesión 2 : a) trayectorias laborales y profesionales; $b$ ) vida familiar $y$ afectiva; c) miradas de Chile actual.

A excepción de dos casos que residen actualmente en la V Región, todos los entrevistados de esta muestra viven en la Región Metropolitana. Del total de entrevistados, 11 hicieron trabajo político en diversas regiones en dictadura (Antofagasta, Ovalle, Biobío, Araucanía, ex Los Lagos y Aysén).

\section{Ética y consentimiento informado}

Todos los entrevistados firmaron el protocolo de consentimiento informado, señalando sus condiciones de anonimato y difusión de resultados. Sólo 5 entrevistados de la muestra solicitaron aparecer con una chapa: 4 lo hicieron para proteger su 
identidad y uno porque quiso rescatar su nombre político. El resto de los entrevistados decidió usar sus nombres de pila como una estrategia de reconocimiento de sus experiencias de lucha, lo cual es muy importante para la interpretación generacional que propone este artículo.

\subsection{Presentación de categorías de análisis}

Comparación de itinerarios biográficos; estructura narrativa del relato (NVIVO 10).

El análisis que presenta este artículo contrasta la evaluación global de la militancia con las distintas miradas de Chile actual a través de las siguientes subcategorías de análisis.

Cuadro 2

Sintesis de categorías de análisis

\begin{tabular}{|c|c|}
\hline Evaluación de la militancia & Miradas de Chile actual \\
\hline $\begin{array}{l}\text { Ideas influyentes de la formación } \\
\text { política }\end{array}$ & Temas pendientes de la democracia \\
\hline Ideas o tesis políticas erróneas & Razones de la desmovilización \\
\hline $\begin{array}{l}\text { Experiencias rescatables de la lucha } \\
\text { antidictadura }\end{array}$ & $\begin{array}{l}\text { Despertar de la movilización social } \\
(2006-2011)\end{array}$ \\
\hline $\begin{array}{l}\text { Impacto de la crisis de la izquierda } \\
\text { mundial y nacional }\end{array}$ & $\begin{array}{l}\text { Formación de nuevos referentes } \\
\text { políticos }\end{array}$ \\
\hline $\begin{array}{l}\text { Contradicciones políticas e ideológi- } \\
\text { cas con la transición }\end{array}$ & Visiones de futuro. \\
\hline
\end{tabular}

\section{Presentación de resultados y discusión de hallazgos}

\subsection{Luchas y derrotas}

Nosotros, en un periodo muy corto de tiempo, vivimos experiencias gigantescas que no se van a repetir. Son irrepetibles. La Unidad Popular fue una épica; la lucha contra la dictadura fue otra épica y, si querís, todo los 90 fue 
otra épica de resistencia (...) Muchas veces, cuando estos cabros presuntuosos de los pingüinos [se refiere a todo el movimiento estudiantil], después de los 2000, las marchas, todo (...) yo les digo: [enfatiza] “PPara un poquito! ¡tres vidas, tres vidas vas a necesitar para vivir lo que yo viví! (César, PC-FPMR, comunicación personal)

Tal como afirmamos en la discusión conceptual y como lo sugiere la cita que inicia este apartado análisis, optar por una aproximación generacional de las identidades militantes supone presentar una problematización del tiempo histórico y del rol que les tocó desempeñar a los entrevistados, en tanto grupo que se reconoce como participante de una misma lucha colectiva. Sin embargo, es importante insistir en que, más que la pertenencia a determinadas organizaciones políticas, el legado ético y político de la lucha antidictatorial es el hito que forja las identidades generacionales, cuyo rasgo común es la sensación de haber formado parte de una misma épica; que tiene su génesis en la crisis de la Unidad Popular, alcanzando su fase más intensa en la década de los 80 y que hace crisis con el proceso de institucionalización de la actividad política, luego del plebiscito de 1988.

En términos biográficos, la clausura de un largo e intenso ciclo de movilización popular contra la dictadura coincide con el fin de la juventud de los militantes y de los sueños que la definieron. Sin embargo, sus experiencias generacionales deben entenderse más allá de las etapas del ciclo vital por el que pasaron los entrevistados. Después de los años agitados de militancia comprometida, no solo enfrentan cambios biográficos significativos, tales como el inicio de la vida laboral o sus responsabilidades parentales y familiares ${ }^{8}$. Además del desafío de reconstruir la propia vida, en términos generacionales, lo más difícil para ellos

\footnotetext{
8 La reconstrucción detallada de las trayectorias laborales y emocionales de los entrevistados constituyen el material de un próximo artículo centrado en los aspectos propiamente biográficos de la transformación de la militancia.
} 
y ellas es comprender el cambio de época al que están asistiendo. Deben adaptarse a una transformación radical de la interpretación del tiempo histórico, de su ritmo y de su dirección.

Con la llegada de la democracia y el fin de la Guerra Fría, no solo se acaba el propósito central de la lucha política (derrocar a Pinochet), sino que las ideas de izquierda se vuelven vertiginosamente parte del pasado: arreadas las banderas tradicionales de los sindicatos y los partidos políticos, termina la era de la lucha heroica y colectiva para dar espacio a los desafíos individuales (Pudal, 2011), imponiéndose un sentido común abrumador de orden y estabilidad ${ }^{9}$.

El balance sobre la derrota político militar y las restricciones de la democracia protegida permiten encontrar los límites de la valoración de la lucha heroica y desinteresada con la que los entrevistados narran su compromiso político en la década de los 80 . Aunque en la gran mayoría de los casos el recuerdo de su participación en la lucha antidictatorial es nostálgico, especialmente a la hora de rescatar el sentimiento comunitario que caracterizó a la militancia juvenil, casi todos los entrevistados hacen una evaluación crítica de las categorías de análisis que tuvo la izquierda chilena para leer su propia transformación, en los albores de la democracia y en plena caída de la cortina de hierro ${ }^{10}$.

\footnotetext{
Con el fin de dar cuenta de las transformaciones del militantismo, Pudal (2011) habla de "retribución", para referirse al cuestionamiento de la lucha heroica y al proceso de incorporación de los militantes al poder; y de "distanciamiento", para definir los procesos de desvinculación cuando se acaban los grandes referentes colectivos.

10 Respecto del impacto de la caída del socialismo (1989-1990), en términos generales, los entrevistados lo señalan como un evento histórico externo, pero no generacionalmente marcador. No obstante, hay matices interesantes dependiendo de la cercanía de los entrevistados con las experiencias socialistas: algunos militantes comunistas que vivieron periodos largos en la URSS o en otros países del Este, declaran un impacto directo y mayor por la crisis del socialismo. Para la mayoría de los entrevistados, el impacto cultural del fin del socialismo europeo estriba en que fue el último evento que selló la larga crisis de la izquierda chilena. Cuando se les consulta directamente por este hito, señalan que fue un evento desmoralizador, porque marca la globalización de la derrota y el fin de una concepción histórica de acción colectiva.
} 
El proceso de institucionalización de la actividad política y la crisis de los partidos de izquierda generó la desvinculación de 14 de 26 de nuestros entrevistados. El análisis comparado de casos muestra que las desvinculaciones del periodo 1988-1990 son una consecuencia directa del proceso de fragmentación de las izquierdas: la salida de los militantes del MIR (9 casos) puede considerarse forzosa, pues responde a la disolución de sus organismos de base. Las desvinculaciones de los comunistas, JJCC y FPMR (5), se producen en 1990, sobre todo, después del Octavo Congreso de las Juventudes Comunistas (1990). Salvo dos casos que se desvincularon temporalmente, la militancia socialista permanece en el partido, aunque en posiciones marginales después que el sector renovado asumiera el control del PS.

Estos antecedentes permiten afirmar que, cuando los militantes y exmilitantes evalúan el rol político que desempeñaron como generación, la opinión mayoritaria, con distintos matices, es que su experiencia en la lucha antidictadura fue sencillamente desperdiciada o relegada a un rol secundario, tanto por los partidos donde militaban como por los gobiernos democráticos.

Aun cuando varios de los militantes de esta muestra trabajaron como funcionarios de gobierno en la primera década de los 90 (5 socialistas, 3 independientes), declaran que no tuvieron ninguna influencia en las grandes decisiones partidarias, ni mucho menos en los temas importantes de la administración del Estado. Para quienes se desvincularon y se dedicaron al trabajo comunitario, al alero de organismos no gubernamentales o en municipios (7 casos), la disolución de diversas organizaciones sociales, en un contexto de desvalorización radical del legado de las izquierdas, refuerza su cuestionamiento a la falta de democracia interna de sus partidos de origen y su consecuente pérdida de vinculación con bases sociales amplias. Para algunos de ellos la frustración fue tal que, por años, rehusaron hablar de su militancia juvenil. Sin embargo, hoy defienden la idea de que el trabajo comunitario fue una forma distinta de militar. Para un tercer grupo de entrevistados (8 casos) que, por tener antecedentes de prisión política 
o debido a una clandestinidad prolongada sobrevivieron como trabajadores independientes, la sensación de exclusión y aislamiento político fue mucho mayor.

Vemos cómo, con distintas intensidades, militantes y ex militantes viven el desfase de sus formas de existencia colectiva. Creemos que el proceso de histéresis que varios de ellos experimentan en los primeros años de democracia, se explica porque todas las prácticas políticas que los identificaron, incluso sus estéticas de lucha, quedan obsoletas en un periodo muy corto. Los jóvenes de 1988 son considerados viejos en 1990 y llamados a ajustarse rápidamente a los "nuevos tiempos". Iván recuerda la reacción de un amigo cercano, después de salir de la cárcel por razones políticas:

Y me acuerdo que íbamos por la Gran Avenida y este huevón [refiriéndose a su amigo que sale de la cárcel] miraba (...) y me dice: "Bajémonos en el [paradero] 14 y vamos al [bar] Safari a tomarnos unos copetes". Puta, pero sabes, es que el Safari ahora es una ISAPRE, huevón. ¡Ya! y más allá. En el [paradero] 20 (...) “¿te acuerdas del [bar] Crucial”. Es que ahora está el Banco del Desarrollo. Entonces, este güevón me decía: [Evoca la expresión] “¡Conchetumadre! No hay ninguna güevá que yo conocí". Y curiosamente, yo no sé si fue mala suerte, pero todos los lugares [que él quería recordar] eran Isapres, Bancos. Entonces, simbólicamente para él, era la salud privada, la banca privada, que se habían tomado todos los espacios donde conspirábamos. (Iván, militante del PS Almeyda, comunicación personal)

Juan Carlos, por su parte, describe su proceso de cambio de prioridades y señala que fue similar entre varios miembros de su generación:

Yo creo que el clima es la tristeza (...) Hay un grado de tristeza que se empieza a generar, porque tu sentís que tenís que, como tu bien dijiste, "reconvertirte", pero ya 
no reconvertirte en el sentido de que... como una estrategia subversiva como la que habíamos hablado en un principio, sino que iya tienes que reconvertirte de verdad, cachái! (...) Porque, uno se empieza a meter en esa lógica de armar una cierta consistencia familiar, por un lado. $\mathrm{Y}$ a desarrollar un buen trabajo, en el fondo. Como que esas cosas, yo creo que son las prioridades de muchos... de muchas personas. (Juan Carlos, ex militante del MIR, comunicación personal)

Comprendemos cómo, en este contexto de profunda transformación de las formas de participación social y política, la discusión sobre la derrota de las formas de lucha radical y el reconocimiento político de esta militancia fueron los más difíciles en términos éticos y humanos. El problema de la viabilidad de estas formas de lucha y la participación electoral había sido la causa principal de la división del FPMR y el MIR (1987). Sin embargo, el análisis de casos muestra que ésta fue una discusión que quedó inconclusa, en parte debido al descrédito de estas formas de movilización en el contexto democrático, pero también como consecuencia de la crisis interna de los partidos del ex MDP. El cruce de los diversos relatos muestra que, a mediados de la década de los 90, la reconstrucción de la experiencia política en las organizaciones armadas resultaba completamente extemporánea y controversial a los desafíos que debían enfrentar los partidos en ese momento. Así lo explica César, quien se desempeñó como oficial internacionalista del FPMR:

Cuando nadie daba un peso por nosotros, incluso estos que son aliados nuestros hoy día [refiriéndose a los partidos de la Nueva Mayoría], no daban una chaucha por nosotros ¡nada, nada! ¡nos habían condenado ellos mismos! Nos decían los dinosaurios, que estábamos en proceso de extinción. ¡Fue un periodo muy duro! (César, FPMR- Militante PC, comunicación personal) 
Este fragmento muestra cómo los militantes que se habían formado para impulsar la salida insurreccional deben constatar la obsolescencia de las categorías políticas que les habían servido para orientar su acción y darle sentido al trabajo militar y/o de base. En estas condiciones, el sabor más amargo de la derrota surgía de una dura evaluación de sus estrategias políticas: el camino de la insurrección popular no solo había sido un fracaso político que les había costado muchas vidas. Había sido sencillamente una ilusión alimentada por una sobrevaloración del éxito y la masividad de las Jornadas de Protesta Nacional $(1983-1986)^{11}$.

Sin embargo, es preciso constatar que, cuando los entrevistados actualizan el debate sobre la derrota político militar, presentan matices interesantes respecto de la evaluación que primó en la década de los 90. Especialmente quienes conocieron de cerca la discusión interna de las estructuras militares del MIR y el FPMR son claros en señalar que la derrota militar de las fuerzas armadas regulares de la dictadura nunca estuvo en el horizonte de las políticas insurreccionales ${ }^{12}$. De este modo, Manuel y Marcos aclaran que la derrota más grande para la izquierda no fue la militar, sino la imposición de un concepto restringido de democracia. En esas circunstancias y ante el pasaje de varios de sus dirigentes a la Concertación de Partidos por la Democracia, al MIR se le hizo imposible avanzar hacia la construcción de un partido político legal ${ }^{13}$. Haber disuelto la organización fue, a juicio de Manuel, un gran error que todavía lamentan:

11 La tesis de la sobrevaloración de las Jornadas de Protesta Nacional, en un contexto de implantación del capitalismo neoliberal, ha sido trabajada por varios autores a través de los años: Guillaudat y Mouterde (1998); Valdivia et al. (2008); y Álvarez (2011).

12 Esta evaluación corrobora la tesis trabajada por Rolando Álvarez (2011) sobre el sentido de la Política de Rebelión Popular de Masas del PC.

13 También, a juicio de la mayoría de los entrevistados y entrevistadas del MIR, el asesinato de Jécar Neghme Cristi, el 4 de septiembre de 1989, habría sido una operación de inteligencia muy eficaz de la Central Nacional de Informaciones (CNI) para impedir la rearticulación política del MIR en democracia. 
No era que íbamos a someter militarmente a la dictadura ¡no! Queríamos someter políticamente a los militares. Entonces, y eso fue el grueso error que se cometió, incluido nosotros [refiriéndose a la disolución del MIR] (...) aunque hay gente dentro del MIR que planteó esa tesis (...) que había que prepararse ya, por ejemplo, había que plantearnos que había que construir un partido legal. (Manuel, exmilitante del MIR, comunicación personal)

Es decir, quienes nos derrotan, finalmente, no son las Fuerzas Armadas: quienes nos derrotan finalmente son las viejas concepciones políticas, nos derrota aquella mirada que plantea que la única forma de salir de la dictadura es negociando con ella y en súper malas condiciones, cediendo de forma vergonzosa elementos que, claramente, podrían haberse negociado de otra forma. (Marcos PC-FPMR/Autónomo, comunicación personal)

Más allá de las grandes discusiones partidarias, es importante destacar que, cuando los entrevistados repasan la década de los 90 en términos subjetivos, la definen como un periodo de desconcierto y tristeza, en el cual vivieron la soledad de la pérdida de referentes políticos: la desaparición de los grupos de pertenencia y la constatación de las consecuencias de la desmovilización social les generó, además, mucha incertidumbre. A continuación, otros dos entrevistados explican cómo se sentían a principios de los noventa:

¡Oscurantismo total, la hueá del neoliberalismo avanzando y los países socialistas derrumbados, la izquierda "sálvese quien pueda", algunos transformándose en los mejores capitalistas del mundo! (...) y yo me sentía, así como... me sentía totalmente huérfano, entonces, el único refugio era la familia, eran los espacios más íntimos, pero en términos políticos [nada] (...). (Alejandro, exmilitante Juventudes Comunistas, comunicación personal) 
Sí, en esa época (...) iyo creo que no era depresión, ah! ¡porque igual yo hacía hartas cosas! (...) pero, yo creo que era un dolor, así como muy intenso y esa sensación, además, de estar como en el desierto, como en un páramo (...) ¡la soledad [ríe] es cuando todos tus referentes desaparecen poh!, ya no están, no están más. Aparte de que no existe nada de lo que tú formabas parte, de tus grupos de referencia, tus amistades. (Gloria, exmilitante del MIR, comunicación personal)

La forma en que los entrevistados describen su proceso de repliegue permite abordar las razones de la desmovilización: los casos muestran que, si bien habían recuperado la ansiada democracia, el proceso de institucionalización de la participación política quedaba vacío socialmente. No solo porque muchos militantes se van de las organizaciones de izquierda, sino porque las formas de acción política que conocieron dejaron de tener sentido.

\subsection{Razones de la desmovilización (1990-2006)}

Cuando los entrevistados elaboran las razones más profundas de la desmovilización, es posible distinguir una importante asociación entre las razones propiamente políticas y las económicas y culturales. Respecto de las primeras, la gran mayoría de los entrevistados coincide en que la desmovilización fue una estrategia deliberada de los gobiernos de la Concertación que, a partir de 1990, inauguraron formas controladas de participación política. La falta de apoyo a iniciativas de base fue, a juicio de Leo, una decisión política. Así, la llegada de la democracia significó la consagración de relaciones clientelares entre el Estado y la ciudadanía. Los distintos mecanismos de cooptación política de diversos actores sociales, constituye, desde nuestro punto de vista, una clave muy importante para comprender las lógicas de la desmovilización de la década de los 90.

Básicamente, porque hubo una decisión política de no apoyar iniciativas de base. $\mathrm{O}$ sea, se burocratizaron a tra- 
vés el FOSIS [Fondo de Solidaridad e Inversión Social], después eso ya ni siquiera las ONG, sino el clientelismo. El clientelismo sería la forma final de censurar, de inhibir el natural movimiento social que hay en la historia. El clientelismo es una forma de participación, absolutamente contralada. (Leo, exmilitante de las Juventudes Comunistas, comunicación personal)

Luego, la consolidación del neoliberalismo en la vida cotidiana fue una de las transformaciones culturales de mayor impacto político, precisamente debido a su eficacia para desarticular las lógicas de acción comunitaria que habían prevalecido en la lucha antidictadura. Aunque la masificación del consumo y el endeudamiento tuvo indudables efectos disciplinantes en la población, fue también muy eficiente para crear una sensación de libertad económica y política.

No obstante, cuando los entrevistados refieren el impacto cultural del neoliberalismo, reconocen que esta es una evaluación que hacen gracias a las herramientas de análisis que tienen hoy. La gran mayoría señala que, a principios de los años 90, les era muy difícil interpretar lo que estaba sucediendo. Reconocen abiertamente que soslayaron el impacto cultural de las transformaciones neoliberales y, en general, de los cambios del capitalismo mundial. El cuadro 3 sintetiza las razones de la desmovilización más comentadas por los entrevistados. 
Cuadro 3

Sintesis de las razones de la desmovilización

\begin{tabular}{|l|l|}
\hline Razones políticas & $\begin{array}{l}\text { Razones económicas y } \\
\text { culturales }\end{array}$ \\
\hline $\begin{array}{l}\text { Profesionalización de la política y acuerdos } \\
\text { cupulares. Énfasis en la política institucional. }\end{array}$ & $\begin{array}{l}\text { Individualismo, privatiza- } \\
\text { ción de la vida, lógicas de } \\
\text { consumo. }\end{array}$ \\
\hline $\begin{array}{l}\text { Partidos se convierten en grupos de lotes que } \\
\text { se disputan el control del Estado. Al volcarse } \\
\text { al Estado, los partidos se desvinculan de las } \\
\text { bases sociales y del mundo popular. }\end{array}$ & $\begin{array}{l}\text { Pérdida de frontera ideo- } \\
\text { lógica entre la derecha y la } \\
\text { izquierda. }\end{array}$ \\
\hline $\begin{array}{l}\text { Política deliberada de desmovilización } \\
\text { expresada en diversas formas de clientelismo } \\
\text { político (fondos concursables). }\end{array}$ & $\begin{array}{l}\text { Gana el proyecto democrático burgués. La caí- } \\
\text { da del socialismo es un evento desmoralizador. }\end{array}$ \\
\hline $\begin{array}{l}\text { Desaparece Pinochet como foco de conflicto } \\
\text { que justifica la movilización social. }\end{array}$ & \\
\hline
\end{tabular}

Fuente: elaboración propia con base en análisis de entrevistas.

A partir del análisis de las razones económicas y culturales, cabe señalar que entre los militantes hubo algunos (2 casos) que declararon las contradicciones de los códigos y las estéticas del militantismo de izquierda para leer las transformaciones culturales que Chile experimentó como consecuencia indirecta de las políticas económicas del régimen. A este respecto - y de manera anecdótica-, María Paulina relata cuánto se sorprendió la primera vez que conoció a jóvenes new waves, durante el Primer Festival de Música thrasher, realizado en el foro de la Universidad de Concepción, en 1986:

Y llegan con dos amigos que estaban reclutados para la Juventud Rebelde [Miguel Enríquez] de ahí del [Liceo] Enrique Molina; con los pelos parados, vestidos de negro, con los labios negros, me acuerdo. $\mathrm{Y}$ yo los miro con cara de, por ser, ique significaría esto! (...) Bueno, una hora después, hora y media después, ya toda esta cosa así en que yo me estoy familiarizando, ese día, con todas 
estas rarezas estéticas, siento un estallido de botella y el piño [multitud de personas] que estaba ahí escuchando en el foro abajo, [en las] las escalinatas de abajo, empiezan a haber peleas, peleas violentas (...). Yo con mis códigos de violencia en la cabeza [bajo la escalera] ¡Había que parar esto! y estos enanos me agarran y me dicen: [Recuerda la expresión] -“Para... ¿Dónde crees que vas? ¡cómo te vas a ir a meter ahí! ¡olvídalo, si esta la cagada! ¡te van a sacar la chucha!". (María Paulina, exmilitante del MIR, comunicación personal)

Con estos antecedentes y tal como lo muestra la investigación antropológica de Benítez y González et al. (2016), es posible afirmar que, en paralelo al movimiento político antidictatorial, estaba madurando otro tipo de resistencia cultural que ya no podía ser leída desde los clivajes tradicionales del militantismo de izquierda. Empero, a pesar de las evidencias del cambio cultural que estaba frente a sus ojos, pasarán varios años antes de que algunos militantes se dediquen profesionalmente a la comprensión de las nuevas expresiones estéticas de la juventud. Primero, experimentarán el desencanto y una profunda soledad política. La pérdida de sus referentes generacionales ayuda a comprender la sensación de abismo y desengaño que acompañó las vivencias de una época gris y confusa que, incluso hoy, les es difícil explicar.

\subsection{Temas pendientes de la democracia}

A nivel macro político, además de los evidentes amarres de la institucionalidad autoritaria y sus deudas en materia de derechos humanos, los entrevistados distinguen otros dos temas culturales importantes: 1) el problema de la democratización de los medios de comunicación, junto con libertad de acceso a otros bienes culturales, y 2) los derechos sexuales y reproductivos de las mujeres y las minorías sexuales, cuya discusión fue muy difícil en la década de los 90, debido al conservadurismo de las elites políticas y a la influencia de la Iglesia católica que, para ese en- 
tonces, también había transformado profundamente su vínculo con las comunidades cristianas de base, especialmente después del cierre de la Vicaría de la Solidaridad (1976-1992).

Para algunos entrevistados, las escandalosas cifras actuales de concentración de medios, tanto en prensa escrita como en televisión, son una responsabilidad de los gobiernos de la Concertación y uno de los principales problemas de la democracia en Chile: los grandes grupos económicos tienen el control casi absoluto de la opinión pública. Leo y Marcos refieren la importancia de la existencia de medios independientes en dictadura y que fueron desapareciendo por no poder competir con los criterios de rentabilidad de los grandes grupos empresariales ${ }^{14}$.

Era decir la transición democrática significa democratizaciones en la esfera de lo simbólico. Y eso es comunicación entera. Comunicación de cultura, para ponerlo en la clave más sociológica. (Leo, exmilitante de las Juventudes Comunistas, comunicación personal)

Los medios de comunicación, digamos, que habían enfrentado a la dictadura - "Análisis", "Cauce", "APSI", "Fortín Mapocho" - pierden todo el apoyo, digamos, internacional solidario, y aquí son boicoteadas abiertamente por los nuevos funcionarios del Estado democrático. (Marcos, PC-FPMR/Autónomo, comunicación personal)

\footnotetext{
14 A fines de 2015, un estudio de Luis Adolfo Breull para el Consejo Nacional de Televisión, reveló que los cuatro principales operadores en cada sector de medios en Chile concentran más del $90 \%$ del mercado: en la TV abierta y de pago, el índice de concentración alcanza el 91\%, mientras en prensa, La Tercera y El Mercurio concentran un $98 \%$. Por su parte, el control de las radioemisoras registra una concentración del $78 \%$ de la audiencia y el $84 \%$ de la inversión publicitaria. Los principales controladores son el grupo español PRISA, Copesa y el grupo Luksic. Fuente: El Desconcierto 24-08-2016. Recuperado de http://www.eldesconcierto. cl/2016/08/24/informe-revela-que-la-concentracion-de-medios-en-chile-es-unade-las-mas-altas-de-la-region/
} 
Por otro lado, el proceso de institucionalización del movimiento de mujeres, que se expresó en la creación del Servicio Nacional de la Mujer (1991), sacrificó la autonomía de sus organizaciones de base. Su traducción al lenguaje de las políticas de gobierno de la Concertación, generó una manera paternalista y conservadora de entender las políticas de género, eclipsando la perspectiva feminista y autónoma que había madurado en diversas organizaciones de mujeres durante la lucha antidictadura. La discusión en torno a la institucionalización o autonomía fragmentó al movimiento de mujeres que, como otros, también perdió su vinculación directa con las organizaciones populares. Así lo recuerda Lucía ${ }^{15}$ :

Bueno, eso fue la cosa un poco divertida, porque como que las banderas tradicionales, sindicales, o incluso estudiantil, como que estuvieron medio de baja en esos años, pero, en cambio, hubo esta otra cosa (...) la agenda estatal del género. (...) Hubo una cierta apertura con la homosexualidad eso sí. Eso era como una puertita. Ahí hubo algún nivel de cambio moderado, pero hubo. Pero, en cambio, (...) lo del aborto, en los derechos reproductivos de la mujer ¡era una güevada brutal! Y eso era como el lado más oscuro del SERNAM [Servicio Nacional de la Mujer]. Toda la política de sexualidad y que ha sido vergonzosa, gracias a los democratacristianos. (Lucía, exmilitante del MIR, comunicación personal)

El abordaje de los temas pendientes de la democracia durante la primera década de los 90 permite identificar las continuidades entre las viejas y las nuevas luchas políticas. El renacimiento de la movilización estudiantil (2006-2011) y de la acción colectiva feminista (2018-2019) parece estar marcando la agenda programática de una nueva izquierda, comprometida con una transformación

15 Para más detalles sobre la institucionalización del movimiento de mujeres, ver el trabajo de Ríos et al. (2003). 
social del modelo político y cultural impuesto por la dictadura. Sin embargo, pese a las esperanzas que abre el nuevo ciclo de movilización social, los entrevistados observan con reserva el proceso de construcción de una alternativa de izquierda viable y sostenible en el tiempo. El último apartado profundiza la evaluación del contexto político actual.

\subsection{Miradas de Chile actual y desafíos de la nueva izquierda chilena}

De manera unánime y corroborando la evidencia empírica de algunos trabajos recientes sobre el impacto político de las movilizaciones estudiantiles (Avendaño, 2014; Durán y Muñoz, 2019), los entrevistados coinciden en que los años 2006 y 2011 marcaron un punto de inflexión que puso fin al silencio y al letargo de la década de los 90, e inclusive de la primera década del siglo XXI.

Así, otra dimensión importante de la interpretación generacional que propone este artículo es el modo en que los militantes piensan su relación con las nuevas generaciones y las alternativas de futuro. Tal como lo afirmáramos en el apartado teórico (Muñoz 2011; González 2012, 2015; Benítez y González et al., 2016; Longa, 2017), la configuración de una identidad generacional está construida desde la referencia a las nuevas y a las viejas generaciones. Por lo tanto, para narrarse generacionalmente, los entrevistados necesitan construir una comparación de la propia experiencia política con la de los nuevos militantes. Es por eso que, a la hora de evaluar las posibilidades de un proyecto político de izquierda alternativo al neoliberalismo, la mayoría de ellos expresa cautela o simplemente desconfianza respecto del papel que les tocará desempeñar a las nuevas generaciones políticas. ¿Cuáles son las razones de la desconfianza en las nuevas dirigencias políticas?

Concretamente, las reservas respecto al rol del Frente Amplio (FA 2017) estriba en la inexperiencia política de un conglomerado cuya dirigencia y base social provienen casi exclusivamente de la movilización estudiantil. Aunque destacan las habilidades 
comunicacionales de los líderes del FA para imponer una agenda política en tan poco tiempo (se refieren a la campaña electoral de 2017), tienen dudas sobre sus capacidades de hacer las transformaciones que dicen representar. A pesar de sus auspiciosos resultados electorales $(20+1)$ y, precisamente, por la masificación de las carreras parlamentarias, algunos entrevistados creen que se trata simplemente del surgimiento de una elite política de recambio, que le está disputando el poder a la desprestigiada Nueva Mayoría (2013-2017).

En segundo lugar, todos los entrevistados piensan que la forma en que los nuevos actores definen el conflicto político es difusa: la crítica al neoliberalismo engloba todo el orden social, pero no expresa una estrategia clara de acción en el largo plazo. Por otro lado, los militantes socialistas todavía creen que la construcción de un programa de reformas tan profundas requiere una alianza política amplia con todos los sectores progresistas. Sin embargo, reconocen la imposibilidad de dicho acuerdo, debido al desprestigio global de la política y de la Nueva Mayoría. En suma, a pesar de la pérdida de legitimidad política del modelo social y económico heredado de la dictadura, los entrevistados creen que actualmente no existen las condiciones para iniciar un proceso de transformación social tan grande como el que tuvo lugar en los años 60 del siglo XX.

Yo soy de los que estábamos entre los que fuimos derrotados de una opción política, que no quiso asumir la derrota. Y [otro] que se apitutó en alguna parte, sobre todo, para poder tener pega (...) y después resulta que aparece en el Frente Amplio diciendo: “yo creí en la Concertación [de Partidos por la Democracia], pero fui defraudado”. ¡En 10 años más van a decir lo mismo del Frente Amplio! (...) porque estructuralmente no hay fuerza social que empuje un proceso como el que empezó [antes de 1973]. (Pablo, exmilitante de las Juventudes Comunistas, comunicación personal) 
Bueno, yo no creo que sean tan mesiánicos [refiriéndose a las dirigencias del Frente Amplio], más bien se quedan cortos, es muy difusa la propuesta (...). Porque, mesiánico sería si tuvieran tremenda convicción en una utopía irreal, pero ni siquiera tienen la tremenda convicción. (...) hay una dificultad para imaginar otra cosa (...). Lo que se derrumba no es el modelo. Lo que se derrumba es (...) la inviolabilidad del modelo. ¡Al fin se puede decir que no está funcionando! ¡Y la evidencia es el desastre en educación y el desastre en la cantidad de viejos pobres, poh! (Lucía, exmilitante del MIR, comunicación personal)

Un tercer y último flanco de críticas es la falta de diálogo intergeneracional. A juicio de la gran mayoría de los entrevistados, en su crítica global a las viejas generaciones la nueva izquierda omite las experiencias de lucha de las décadas del 70 y del 80. Sin embargo, creen que esta omisión no es necesariamente deliberada. Creen que se debe a los vacíos y discontinuidades en la narración de las trayectorias históricas de movilización de las izquierdas.

Notamos que, en la evaluación del desempeño de las nuevas generaciones, militantes y ex militantes conservan la misma sensación de desplazamiento de sus experiencias políticas. Nuevamente se definen como actores secundarios de la construcción de un nuevo proyecto de izquierda. No obstante, creen que ahora sí pueden hacer una contribución significativa, precisamente rescatando y trasmitiendo sus experiencias de lucha. Hacerse cargo del pasado tiene, hoy día, un indudable valor político para pensar en una futura rearticulación de la izquierda. Por tanto, el futuro está todavía abierto:

[Refiriéndose al futuro de la izquierda] Yo lo veo como algo está en construcción, que tiene un gran problema que es el tema de la continuidad y discontinuidad generacional, donde la contradicción intergeneracional es 
muy evidente y donde, al parecer, nuestra generación, la generación del 80, queda subsumida a los liderazgos de las generaciones más jóvenes, que piensan básicamente que dominan todo. (Leo, exmilitante de las Juventudes Comunistas, comunicación personal)

En la medida que esta izquierda, que se rearticula y que tiene capacidad política, también se haga cargo de su pasado en términos de los éxitos, de los fracasos y de las posturas que hubo, cachái. Porque aquí en el tema de la apertura democrática, todo el mundo el tema de la lucha armada y el tema de los cambios violentos fueron pensados como unas locuras de jóvenes o tratados así (...) y eso, yo creo que le hizo muy mal a esta democracia. (...) Es distinto un poco lo que pasó en el Frente Amplio en Uruguay. Yo creo que eso es un tema que hoy día viene, darle esa oportunidad que entren esas personas también [Entrevistadora];Ah! Tú te refieres a las exclusiones de la gente que había militado en los aparatos armados. ¡Sí, poh! Eso es lo que creo yo que queda hoy día pendiente en la historia. Como se rearticulan todas [las fuerzas]. (Juan Carlos, exmilitante del MIR, comunicación personal)

Por último, la creación de organizaciones que permitan recomponer el vínculo con amplias bases sociales y el establecimiento de mecanismos democráticos de deliberación interna, son condiciones irrenunciables para la maduración de una alternativa política a la derecha. Sin embargo, dichas condiciones aparecen también como un desafío pendiente de la democracia y de la nueva izquierda.

\section{Comentarios finales: ¿luchas de ayer?}

El presente artículo explora una interpretación generacional de las experiencias de militancia de izquierda, construida a partir de la evaluación que los militantes y exmilitantes hacen de 
su participación en la lucha antidictadura y del modo en que vivieron el proceso de institucionalización de la actividad política. El abordaje de las razones de la desmovilización y de los temas pendientes de la democracia, permite encontrar importantes continuidades con los debates actuales de la izquierda chilena.

Así, el concepto de "identidad generacional" que propone este artículo es útil para mostrar la forma en que los militantes y exmilitantes se piensan como una comunidad que comparte una interpretación similar de su experiencia histórica y política, la cual debe entenderse de manera independiente a la filiación político-partidaria. Aunque los casos reconocen cierta nostalgia por las lógicas de acción comunitaria que caracterizaron la lucha antidictadura y reiteran su sentimiento de solidaridad con los miembros de su generación y con las luchas de pasado, logran hacer una interesante evaluación global y crítica de la época que vivieron.

A partir de esta evaluación hecha en el presente, el concepto de "identidad generacional" es especialmente adecuado para describir el desfase temporal que los militantes enfrentan al iniciar la década de los 90, así como la manera en que piensan su rol político actual: la sensación de haber sido actores secundarios del proceso chileno define su interés por rescatar sus experiencias de lucha política de cara a los desafíos actuales que enfrenta la izquierda chilena. Si en los años 80 los militantes de base tejieron los nexos entre los partidos y la movilización social, haciendo posible su masividad, actualmente, la evaluación crítica y la transferencia de sus experiencias de movilización puede aportar a la reconstrucción de una izquierda diversa y reconectada con amplias bases sociales. Por todas estas razones, estos casos pueden considerarse un eslabón que enlaza las luchas políticas del siglo XX con las del siglo XXI y que podría recomponer los vínculos entre la vieja y la nueva izquierda.

Finalmente, esta primera operacionalización conceptual es útil para identificar los contenidos generales de la narrativa ge- 
neracional de los entrevistados, pero no parece suficiente para una problematización acabada de los procesos de transformación identitaria de los militantes y exmilitantes de izquierda. Es necesario profundizar en otras categorías de análisis biográfico y elaborar, con otros marcos teóricos, nuevas hipótesis interpretativas sobre la influencia que tuvieron de los procesos de profesionalización y la inserción laboral en la transformación identitaria. Así también, es necesario revisar aspectos importantes de la vida emocional de los entrevistados para terminar de entender sus procesos de reconversión. Ambas dimensiones serán material de un próximo artículo.

\section{Referencias}

Aguilar. P y Ramírez, C. (2016). "Generational dynamics in Spain": Memory trasmission of a turbulent past. Memory Studies, Fist published, 18, 1-17 DOI:10.1177/1750698016673237

Alvarez, R. (2011). Arriba los pobres del mundo. Cultura e identidad politica del partido Comunista de Chile entre democracia y dictadura 1965-1990. Santiago de Chile: LOM.

Avendaño, O. (2014). Fracturas y representación política del movimiento estudiantil. Chile. 2011. Última Década, 41, 41-68. Recuperado de https://scielo.conicyt.cl/scielo.php?script=sci_ arttext\&pid=S0718-22362014000200003\&lng=es\&nrm=iso \&tlng=es

Benítez, L., González, Y. y Senn, D. (2016). Punkis y New Waves en dictadura: rearticulación y resistencia de las culturas juveniles en Chile (1979-1984). Revista Latinoamericana de Ciencias Sociales, Niñez y Juventud, 14(1), 191-203. Recuperado de http://www.scielo.org.co/pdf/rlcs/v14n1/v14n1a13.pdf

Bosi, L. (2016). Social movements and interrelated effects: the process of social change in the post-movement lives of Provisional IRA volunteers. Revista Internacional de Sociología, 74(4), 1-12. DOI: http:/ /dx.doi.org/10.3989/ris.2016.74.4.047

Cornejo, M. et al. (2013). Historias de la dictadura militar chilena desde voces generacionales. Revista PSYKE, 22(2), 49-65. Recuperado de https://scielo.conicyt.cl/scielo.php?script=sci_art text\&pid=S0718-22282013000200005 
Cornejo, M. y Rocha, C. (2018). Tell me your history about the chilean dictatorship. When doing memory is taking position. Memory Studies, 1-16. DOI: https://doi. org / 10.1177/1750698018761170

Corvalán, L. (2000). Los partidos políticos y el golpe del 11 de septiembre. Contribución al estudio del contexto histórico. Santiago de Chile: Ediciones Chile América-CESOC.

Cuevas, H. et al. (2015). Los ministros de la Concertación de partidos por la Democracia en Chile. Un análisis de sus capitales político, social y cultural. Revista América Latina Hoy, 71, 121-150. Recuperado de http://revistas.usal.es/index. php/1130-2887/article/view/9363

Cuevas, H. (2015). Elites políticas y trayectorias políticas militantes. El espacio sociopolítico de la izquierda chilena. Revista de Ciencia política, 35(2), 299-325. Recuperado de https:// scielo.conicyt.cl/scielo.php?script=sci_arttext\&pid=S0718090X2015000200003

Espinoza, V. (2010). Redes de poder y sociabilidad en la élite política chilena. Los parlamentarios de 1990-2005. Revista Polis, 26(9), 251-286. DOI: http://dx.doi.org/10.4067/S071865682010000200013.

Fillieule, O. (2015). Propuestas para un análisis procesual del compromiso individual. Revista Sociológica de Pensamiento Crítico, 9(2), 197-212. Recuperado de http://www.intersticios.es/ article/view/15549

González, Y. (2010). Sumar y no ser sumados. Culturas juveniles revolucionarias. Mayo del 68 y diversificación identitaria en Chile. Alpha, 111-128. DOI: http://dx.doi.org/10.4067/S071822012010000100008

González, Y. (2015). El “Golpe Generacional” y la Secretaría Nacional de la Juventud: Purga, disciplinamiento y resocialización de las identidades juveniles bajo Pinochet (1973-1980). Atenea, (512), 87-111. DOI: http://dx.doi.org/10.4067/S071804622015000200006 .

González, Y. y Feixa, C. (2012). La construcción histórica de la Juventud en América Latina. Bohemios, rockanroleros y revolucionarios. Santiago de Chile: Editorial Cuarto Propio.

Guidaullat, P. y Mouterde, P. (1999). Los Movimientos sociales en Chile 1973-1993. Santiago de Chile: LOM. 
Hite, K. 2000. Interpreting Political identity. En When the romance ended. Leaders of de chilean left, 1968-1998 (pp.1-27). Nueva York: Columbia University Press.

Leccardi, C y Feixa, C. (2011). El concepto de generación en las teorías sobre juventud. Revista Última Década, 34, 11-32.

Longa, F. (2017). ¿Existen las generaciones políticas? Reflexiones en torno a una controversia conceptual. Iconos Revista de Ciencias Sociales, 58, 205-224. Recuperado de https://revistas.flacsoandes.edu.ec/iconos/article/view/2051

Mannheim, K. (1993). El problema de las generaciones. Revista Española de Investigaciones Sociológicas, 62, 193-242. Recuperado de http:/ / www.reis.cis.es/REIS/PDF/REIS_062_12.pdf

Melucci, A. (2002). Acción colectiva, vida cotidiana y democracia. México, DF: Colegio de México, Centro de Estudios Sociológicos.

Moyano, C. (2009). Mapu o la seducción del poder y la juventud. Los años fundacionales del partido-mito de nuestra transición (19691973). Santiago de Chile: Ediciones Universidad Alberto Hurtado.

Moyano, C. (2011). Diálogos entre el exilio y el interior. Reflexiones en torno a la circulación de ideas en el proceso de renovación socialista, 1973-1990. Revista Izquierdas, 9, 31-46. Recuperado de https:/ / www.redalyc.org/articulo.oa?id=360133449002

Moulian, T. (2006). Fracturas: de Pedro Aguirre Cerda a Salvador Allende (1938-1973). Santiago de Chile: LOM.

Moulian, T. (2008). Conversación interrumpida con Allende. Santiago de Chile: LOM.

Muñoz, V. (2011). Generaciones. Juventud universitaria e izquierdas políticas en Chile y México (Universidades de Chile- UNAM 1984-2006). Santiago de Chile: LOM.

Muñoz, V. (2017). Militancia, facciones y juventud en el Partido Socialista Almeyda (1979-1990). Revista Izquierdas, 37: 226-260. DOI: http:/ /dx.doi.org/10.4067/S0718-50492017000600226

Muñoz, V. y Durán, C. (2019). Los jóvenes, la política y los movimientos estudiantiles en el Chile reciente. Ciclos sociopolíticos entre 1967 y 2017. Revista Izquierdas, 45, 129-159. Recuperado de http:/ /www.izquierdas.cl/images/pdf/2019/n45/art6.pdf

Ollier, M. (2009). De la revolución a la democracia: cambios privados, públicos y políticos de la izquierda argentina. Buenos Aires: Siglo XXI. 
Oyarzo, C. G. (2017). Desafíos empíricos del uso de la perspectiva biográfica en el estudio de las transformaciones de la militancia anti dictatorial en Chile: Reflexiones teóricas y metodológicas para la enseñanza y aplicación de técnicas cualitativas de investigación al análisis de procesos políticos. Revista Paideia, 61, 35-56. Recuperado de http://www. revistapaideia.cl/index.php/PAIDEIA/article/view/165

Oyarzo, C. G. (2018). La vida entre contiendas. Militancias y sentidos de la participación política en la lucha antidictatorial chilena. Santiago de Chile: RIL.

Pirker, K. (2007). La redefinición de lo posible. Guerra civil y proceso de paz en las biografías militantes de la izquierda salvadoreña. Revista Centroamericana de Ciencias Sociales, 4(2), 3-29. Recuperado de https://dialnet.unirioja.es/servlet/ articulo? codigo $=2881998$

Pudal, B. (2011). Los enfoques teóricos y metodológicos de la militancia. Revista Sociológica, 25, 17-35. Recuperado de https:// revistadesociologia.uchile.cl/index.php/RDS/article/ view $/ 27495$

Ríos, M. et al. (2003). Un nuevo silencio feminista. La transformación de un movimiento social en el Chile de la postdictadura. Santiago de Chile: CEM/ Cuarto Propio.

Valdivia, V., Álvarez, R. et al. (2008). Su revolución contra nuestra revolución. Vol.II. Santiago de Chile: LOM.

Valenzuela, A. (1988). El quiebre de la democracia. Santiago de Chile: FLACSO.

Winn, P. (2013). La revolución chilena. Santiago de Chile: LOM. 